\title{
MEDIDAS DE SEGURANÇA: UM INSTITUTO QUE DITA O RITMO DA NARRATIVA SOBRE O "LOUCO INFRATOR" E CRIMINALIZA A LOUCURA EM NOME DA DEFESA SOCIAL
}

\section{SECURITY MEASURE: AN INSTITUTE WHICH DICTATES THE RHYTHM OF THE NARRATIVE THE "MENTAL ILL" AND THE MADNESS IN THE NAME OF THE SOCIAL DEFENSE}

\section{Anna Kelly Diniz Pires ${ }^{1}$, Thayara Castelo Branco ${ }^{2}$}

RESUMO: Esta pesquisa tem como proposta desencadeadora analisar o instituto das medidas de segurança através da medicina social e da criminologia crítica, bem como trazer à baila os diferentes discursos que compõem a relação entre o crime e a loucura efetivados em tal instituto. O objetivo desse artigo científico é discutir uma correlação entre a psiquiatrização do crime e uma criminalização histórica da loucura visto que a "legitimidade" das medidas de segurança não se dá somente pelo pressuposto de periculosidade, mas também pela raça, classe social e, principalmente, pela cultura do medo.

PALAVRAS-CHAVE: Medidas de segurança. Criminologia crítica. Periculosidade. Defesa social. Louco infrator.

ABSTRACT: The purpose of this research is to analyze the institute of security measures through social medicine and critical criminology, as well as to bring to light the different discourses that make up the relationship between crime and madness effected in such an institute. The objective of this scientific article is to discuss a correlation between the psychiatrisation of crime and a historical criminalization of madness, since the legitimacy of security measures is not only due to the premise of dangerousness, but also by race, social class and, by the culture of fear.

KEYWORDS: Security Measures. Critical Criminology. Danger. Social Defense. Mental ill.

\footnotetext{
${ }^{1}$ Discente do Curso de Direito da Universidade CEUMA. Integrante do Núcleo de Estudos e Pesquisas em Violência e Cidadania - NEVIC da Universidade CEUMA. Bolsista do Programa de Bolsas de Iniciação Científica - PIBIC da Universidade CEUMA. E-mail: dinizkelly@ hotmail.com

${ }^{2}$ Advogada. Doutora em Ciências Criminais pela PUCRS, com área de pesquisa em Violência, Crime e Segurança Pública (2016). Mestra em Ciências Criminais pela PUCRS, com linha de pesquisa em Criminologia e Controle Social (2010). Especialista em Ciências Criminais pelo CESUSC (2008). Membro da Comissão de Direitos Humanos da OAB/MA. Professora da graduação e da pós-graduação da Universidade CEUMA. Docente Pesquisadora integrante do Núcleo de Estudos e Pesquisas em Violência e Cidadania - NEVIC da Universidade CEUMA. Coordenadora da Pós-Graduação em Ciências Criminais da Universidade Ceuma. Professora substituta da UEMA. Pesquisa na área das Ciências Criminais e Direitos Humanos. E-mail: thaybranco@yahoo.com.br
} 


\section{INTRODUÇÃO}

A medida de segurança é um instituto jurídico aplicado às pessoas que cometeram um ato criminoso, mas que, por motivos biopsicopatológicos, não podem responder penalmente por ele. Teoricamente, o objetivo basilar é fornecer segurança à sociedade contra possíveis novos atos de violência por parte dos que sofrem algum tipo de transtorno psíquico. Este artigo se pautará em uma discussão correlativa entre uma criminalização histórica da loucura e a infiltração do campo médico, através da perícia e medicina legal, no campo jurídico, regida pela noção de periculosidade e um discurso ainda permanente de defesa social. Sendo a criminalização da loucura uma discussão histórica, far-se-á necessário recorrer à medicina social e à criminologia crítica em busca de elementos que norteiem a interpretação dessas medidas.

Inicialmente, analisar-se-á o texto penal codificado no tocante às medidas de segurança, seguida do tópico que se atém a discutir sobre o contributo da medicina social para a criação e efetivação das medidas seguranças e todo seu contexto histórico.

Nesse contexto, a criminologia crítica entrará em cena fundamentando a efetividade das medidas de segurança como matriz da defesa social. Por fim, o objetivo central desse artigo será traçar uma linha tênue entre direito/justiça e psiquiatria/'doença' e localizar os elementos para a interpretação desse dispositivo com base em produções bibliográficas e os diferentes discursos e práticas que compõem a relação entre o crime e a 'loucura'.

\section{UM OLHAR DOGMÁTICO ACERCA DAS MEDIDAS DE SEGURANÇA}

A partir de 1984, as Medidas de Segurança (detentiva e restritiva ${ }^{3}$ ) foram estabelecidas no Brasil como instrumentos de proteção social e terapia individual, com natureza preventiva assistencial, fundada na periculosidade de autores inimputáveis e semi-imputáveis de fatos definidos como crimes com o objetivo de prevenir prática de fatos puníveis no futuro, conforme artigos 96 e 97 do Código Penal. O discurso oficial

\footnotetext{
${ }^{3} \mathrm{O}$ ordenamento jurídico-penal brasileiro prevê somente duas espécies de medidas de segurança: uma detentiva, consistente na internação em hospital de custódia e tratamento psiquiátrico e outra restritiva, referente ao tratamento ambulatorial. (art. 96 do Código Penal). De forma geral, a internação em hospital de custódia e tratamento psiquiátrico destina-se, obrigatoriamente, aos inimputáveis que tenham cometido um injusto (crime), punível com reclusão; e facultativamente, aos que tenham praticado um injusto cuja natureza da pena abstratamente cominada seja de detenção (art. $97 \mathrm{CP}$ ). Ademais, o semi-imputável também poderá ter a pena privativa de liberdade substituída por medida de segurança (art. $98 \mathrm{CP}$ ), inclusive na modalidade de internação, se comprovado necessidade de especial tratamento curativo. Quanto ao tratamento ambulatorial, este só é imposto em casos de crimes apenados com detenção.
} 
enfatiza que o propósito socializador das Medidas de Segurança deve prevalecer sobre a intenção de segurança, pois sua aplicação tem por finalidade um tratamentoressocializador, admitindo a segregação de forma subsidiária.

O discurso oficial, alicerçado (ilusoriamente) pelos princípios de humanidade, legalidade, dignidade, devido processo, etc., enfatiza que o propósito socializador das medidas de segurança deve prevalecer sobre a intenção de segurança, pois a base que norteia a aplicação de tal sanção constitui um fim de tratamentoressocializador ${ }^{4}$, admitindo de forma subsidiária a segregação. Consubstanciando a função declarada, Marques (1999, p. 251):

A medida de segurança somente se torna cabível depois que o delinquente, em processo regular, é tido como perigoso. Uma vez comprovada a sua periculosidade, tenta-se livrá-lo dos elementos que atuam nocivamente sobre sua personalidade para torná-lo um ser útil à coletividade.

Nessa esteira, no Brasil com a adoção do sistema vicariante após a "Reforma do Código Penal" em 1984, deixou-se de aplicar medidas de segurança ao imputável, cabendo a partir de então exclusivamente aos inimputáveis e semi-imputáveis ${ }^{5}$ (este quando necessário), vedada à acumulação ou sucessão das duas reações penais, típica do sistema do duplo binário anteriormente adotado.

As medidas de segurança detentiva e restritiva ${ }^{6}$ passam então a ser concebidas como instrumentos de proteção social e terapia individual, com natureza preventiva assistencial, fundada na periculosidade de autores inimputáveis e semiimputáveis de fatos definidos como crimes com o objetivo de prevenir prática de fatos puníveis no futuro, conforme artigos 96 e 97 do Código Penal.

\footnotetext{
${ }^{4}$ Com ressalta Baratta (2002, p. 40$)$ sobre a função curativa e reeducativa das medidas de segurança: "A conseqüência politicamente tão discutível e discutida desta colocação é a duração tendencialmente indeterminada da pena, já que o critério de mediação não está ligado abstratamente ao fato delituoso singular, ou seja, à violação do direito ou ao dano social produzido, mas às condições do sujeito tratado; e só em relação aos efeitos atribuídos à pena, melhoria e reeducação do delinqüente, pode ser medida sua duração".

${ }^{5}$ Neste ponto, o sujeito não pode mais ser destinatário de duas reações penais, aplicadas sucessivamente. A medida de internamento perde sua função de complemento da pena, permanecendo apenas como medida de substituição judicial, quando em causa um semi-imputável. (DOTTI, 1982, p.58)

${ }^{6} \mathrm{O}$ ordenamento jurídico-penal brasileiro prevê somente duas espécies de medidas de segurança, quais sejam: uma detentiva, consistente na internação em hospital de custódia e tratamento psiquiátrico e outra restritiva, referente ao tratamento ambulatorial. (art. 96 do Código Penal). De forma geral, a internação em hospital de custódia e tratamento psiquiátrico destina-se, obrigatoriamente, aos inimputáveis que tenham cometido um injusto (crime), punível com reclusão; e facultativamente, aos que tenham praticado um injusto cuja natureza da pena abstratamente cominada seja de detenção (art. $97 \mathrm{CP}$ ). Ademais, o semiimputável também poderá ter a pena privativa de liberdade substituída por medida de segurança (art. 98 $\mathrm{CP}$ ), inclusive na modalidade de internação, se comprovado necessidade de especial tratamento curativo. Quanto ao tratamento ambulatorial só é imposto em casos crimes apenados com detenção.
} 
Assim, estabeleceu-se que para a efetiva aplicação das medidas de segurança é preciso a existência simultânea de dois pressupostos fundamentais: a) a realização de fato previsto como crime (tipo de injusto); b) a periculosidade do autor ${ }^{7}$.

Como se vê, apesar da Reforma Penal de 1984, a aplicação da medida, tanto de internação quanto de tratamento ambulatorial, pressupõe ao lado da realização de um fato previsto como crime, a periculosidade do agente - a ameaça de praticar outros crimes -, reforçando o pensamento da escola positiva. Nesse sentido, Marchewka (2004,p. 183):

\begin{abstract}
Na produção das imagens do doente mental ele é sempre visto pela tônica da piedade e do medo, da caridade cristã, da intolerância, inclusive da própria família ou da repressão, da vítima ou do criminoso perigoso, sempre numa dualidade aparente dissociada, mas que representa duas faces de uma mesma moeda: a representação do destrutivo, do negativo e do mal social. Isto quer dizer que, ao lado da medida de segurança transparece a demonização dos doentes mentais por aquilo que eles podem significar: o mito da loucura.
\end{abstract}

Percebe-se que muito além de um instituto jurídico, "a medida de segurança é, sobretudo um destino, imposto pelo imperativo da defesa social e traçado em diálogo com uma especialidade médica" (GONÇALVES, 2008).

\title{
2. O CONTRIBUTO DA MEDICINA SOCIAL E SEU CARÁtER POLICIALESCO PARA A CRIAÇÃO DAS MEDIDAS DE SEGURANÇA
}

No século XIX as intervenções médicas executavam um controle social com um discurso do bem-estar "comum”, com caráter preventivo-social. Nesse período, começou a tomar lugar a medicina social, que pretendia interferir nas vidas dos indivíduos e medicalizar a sociedade mais do que os outros setores tradicionais da medicina. Era uma medicina que, aliada ao poder do Estado, medicalizava as diferentes esferas e as diferentes instituições da sociedade. A saúde não tinha, até o século XIX, ligação nenhuma com a sociedade, ela servia para evitar a morte depois do aparecimento dos sintomas.

\footnotetext{
${ }^{7}$ Neste ponto, faz-se interessante ressaltar a crítica de Santos (2006, p. 638): "A crise das Medidas de Segurança decorre da inconsistência desses fundamentos: primeiro, nenhum método científico permite prever o comportamento futuro de ninguém; segundo, a capacidade da medida de segurança para transformar condutas anti-sociais de inimputáveis em condutas ajustadas de imputáveis não está demonstrada".
} 
Para Machado (1978):

\begin{abstract}
A que se tem chamado de medicalização da sociedade- processo que na atualidade cada vez mais se intensifica - é o reconhecimento de que a partir do século XIX a medicina em tudo intervém e começa a ter fronteiras; e a compreensão de que o perigo urbano não pode ser destruído unicamente pela promulgação de leis ou por uma ação lacunar, fragmentária, de repressão do abusos, mas exige a criação de uma nova tecnologia de poder capaz de controlar os indivíduos e as populações tomando-os produtivos ao mesmo tempo que inofensivos; e a descoberta de que, com o objetivo de realizar uma sociedade sadia, a medicina social esteve, desde a sua constituição, ligada ao projeto de transformação do desviante - sejam quais forem as especificidades que ele apresente- em um ser normalizado.
\end{abstract}

Quando o Estado passou a crer que podia intervir e decidir a vida dos indivíduos e da coletividade, a medicina passou a ser a sua vertente de intervenção na saúde. Assim, o objeto da medicina começou a se deslocar da doença para a saúde, ou seja, não pretendia mais somente curar o corpo acometido por uma doença, mas impedir que ele ficasse doente. Por isso, tornou-se um estudo sobre o que causa a doença e visava impedir que o sujeito entrasse em contato com aquilo que pudesse lhe causar a doença.

A medicina social, portanto, foi um novo tipo de saber sobre o homem, que olhava para ele tanto do ponto de vista físico quanto da moral; e que ia além dele, analisando a sociedade que estava à sua volta. Com a impossibilidade da distribuição de castigos e prevenções do Antigo Regime, o castigo foi mais criticado, limitado e, finalmente, substituído pelos novos regimes políticos. Tanto a prisão quanto a polícia e as demais criações do século XIX devem ser entendidas no contexto das principais medidas de controle da população que começariam a ser implementadas naquele século por parte da burguesia já no poder.

O discurso médico foi especialmente útil para esse objetivo. A medicina individual unida à medicina social ou higienismo mostraria que, mesmo quando o sujeito humano tem uma base física forte e temperamental imodificável, "é possível fazer algo em relação a determinados sujeitos portadores de anomalias ou imperfeições, para o bem deles mesmos e de todos" (ANITUA, 2008). Igualmente e de maneiras diretamente relacionadas com a modificação do indivíduo, o caráter e o meio social também poderiam ser mudados. E é sobre esses dois objetivos que atuaria a política guiada por critérios médicos, com o concurso da principal instituição de confinamento do momento: $o$ manicômio. 
Do ponto de vista higiênico, a polícia se revelaria mais eficaz para a "profilaxia" social do que a prisão e, assim, o desenho urbano sem limites ocuparia o lugar autenticamente preventivo e a penitenciária ocuparia o lugar dos castigos, que, a princípio, estavam proibidos pela legalidade nascente. Vale ressaltar que a origem desta instituição não estava relacionada ao castigo, mas sim, com a prevenção, e nela eram encerrados os sujeitos tidos como perigosos e imprestáveis. Antes do século XVIII, o hospital era essencialmente uma instituição de assistência aos pobres. Instituição de assistência, como também de separação e exclusão. "O pobre como pobre tem necessidade de assistência e, como doente, portador de doença e de possível contágio, é perigoso" (FOUCAULT, 1979).

Assim, os primeiros Hospitais Psiquiátricos não foram criados inicialmente com finalidades médicas ou terapêuticas, mas sim considerados estruturas semelhantes a prisões para o confinamento de pessoas "socialmente indesejáveis".

Nessa linha, afirma Anitua (2008):

Todas essas medidas estavam incluídas dentro do prestígio chamado "higienismo". O "controle" era a palavra chave desse movimento. O higienismo sempre esteve impregnado de uma intenção moralizadora, mediante a qual seriam impostas modelos "corretos" de sexualidade e de vida cotidiana, uma das partes mais evidentes dos seus objetivos. Inquestionavelmente, a principal instituição de controle escolhida pela classe burguesa foi a prisão. O método de controle seria, nesta nova ordem, a família, a escola, o exército. Mas o cárcere é a epítome de todos eles, o que com mais clareza impõe a disciplina individual e o controle de massas.

As políticas penais, utilitárias e disciplinares acompanharam o nascimento de uma nova forma de castigar, inerente às transformações sociais e econômicas supracitadas. Esta nova forma, a privação da liberdade, foi generalizada ao longo do século XIX, e só a partir de então em todo mundo ocidental. Era preciso manter a sociedade livre dos indesejáveis tidos como perigosos. Tanto a medicina social/higienismo quanto o positivismo criminológico contribuíram para o movimento de defesa social que legitimou um Direito Penal do autor, fundamentado na periculosidade, afastando-se, nessa medida, do Direito Penal da culpabilidade pelo fato. 


\section{O SURGIMENTO DO INSTITUTO DA MEDIDA DE SEGURANÇA COMO MEIO DE DEFESA SOCIAL}

As medidas de segurança são reconhecidas como sanções penais, fundadas na periculosidade do autor, destinadas aos sujeitos considerados inimputáveis e semiimputáveis, admitidos no imaginário social como "loucos criminosos e perigosos". A ideia de o perigo estar ligado ao louco e, consequentemente, esse louco ser criminoso, configura a medida de segurança como uma invenção criada para sustentar o discurso de defesa social. "Esta, mais que uma defesa social, seria uma paradoxal defesa da pessoa portadora de doença mental contra a sua própria loucura" (JACOBINA, 2004, p. 69).

Tal instituto surge como sanção legitimadora capaz de proteger a sociedade segregando os indivíduos por critério preventivo. Nesse contexto, a fala do "louco infrator" é somente administrável pelo saber psiquiátrico, e destaca-se a ideia de necessidade como a razão da contenção, para além dos limites legais, de entes perigosos. Mesmo em um país tão miscigenado como o Brasil, percebe-se até os dias atuais que "a cor das alas psiquiátricas dos hospitais de custódia não é diferente da cor dos cárceres". (GONÇALVES, 2008).

Punir tornou-se, dentre as novas técnicas de controle, um conjunto de procedimentos dirigidos para modificar os infratores. Mais do que agir sobre o crime, era preciso agir sobre o criminoso, ou seja, sobre aquilo que o tornava criminoso, seus motivos, seus instintos, suas tendências. Na verdade, prevalece ainda no direito uma noção desumanizadora da loucura, fruto do desenvolvimento do racionalismo e do positivismo tão arraigados nas ciências desde a sua origem. Nessa desumanização, a loucura passa a ser uma entidade. Ela passa a ter uma vontade que supera a própria vontade humana e deslegitima o tão discutido livre arbítrio, colocando-se além da punição. A seletividade da justiça, que resulta na cor do cárcere, assim como a tortura carcerária e a violência policial de hoje, é concebida por (SEGATO apud GONÇALVES, 2008), "como a continuidade, numa trama histórica, de uma sequência que começa com a escravidão e com os genocídios perpetrados por agentes das metrópoles coloniais e dos Estados Nacionais".

Nessa seletividade, os loucos herdam o internamento, tornam-se os caracterizadores primários do processo de exclusão. A sociedade ocidental conferiu o status de doença mental à loucura, o desvio mental passa a ser encarado como desvio social, onde as reações sociais são estereotipadas culturalmente. Segundo Becker, o 
comportamento desviante, ou então o desvio, é um "erro publicamente rotulado - é sempre o resultado de um empreendimento” (BECKER, 2008 apud CAIXETA, 2012).

A imposição das regras sociais define a situação vigente, de forma a categorizar o que é ou não apropriado. Assim, afirma que o desvio não é uma qualidade do ato que a pessoa comete, mas uma consequência da aplicação por outros de regras e sanções a um infrator. O desvio, como transgressão à norma, pauta-se numa relação de poder político e econômico entre os indivíduos, sendo que é de maneira seletiva que os representantes da lei, respondendo às pressões da própria situação de trabalho, aplicam a lei e criam as categorias de pessoas estranhas à coletividade (BECKER, 2008 apud CAIXETA, 2012).

\section{MEDIDAS DE SEGURANÇA: UM INSTITUTO QUE PUNE A LOUCURA}

A saúde é um conceito puramente prático, convencional e não tem nenhum significado científico real. Simplesmente significa que a pessoa está indo bem; não quer dizer que a pessoa é particularmente meritória. Na "ideologia da insanidade moderna" expressa através dos jargões científicos dos diagnósticos, prognósticos e tratamentos psiquiátricos - incorporada aos Sistemas de Controle Formal e Informal, “a ideologia é médica, a tecnologia é clínica e o perito é psiquiatra" (SZASZ, 1977). Seguindo esta linha, parece óbvio que as penas detentivas desproporcionais e irresponsáveis- medidas de segurança- estão destinadas à eliminação de inimigos. Esse ciclo vicioso traz resquícios da medicina legal, disseminada no Brasil, a partir do século XVIII.

Nina Rodrigues, propagador do pioneiro movimento de nacionalização da Medicina Legal no Brasil, correlaciona a associação do crime às manifestações degenerativas e seu retorno aos sentimentos indomáveis. Essa associação criada e "cientificamente" identificada nas pesquisas gerou e (ainda gera) consequências diretas na construção do pensamento jurídico-penal, nas práticas político-criminais, no senso comum teórico e em todo o funcionamento do sistema de justiça criminal brasileiro.

A linha racial-evolucionista estruturou a diversidade étnico-cultural e social do Brasil visando, assim, estratégias que possibilitassem compreensões e soluções sobre a questão da unidade nacional. E nessa época o saber médico passou a regular, de forma mais acentuada, a vida individual das populações e das instituiçõos urbanas. Parece que a mistura entre raças de homens muito diferentes produzia um tipo mental sem valor, que 
não servia nem para levar a vida da raça superior, nem da inferior, e não era apropriada a nenhum gênero de vida, afirmava (RODRIGUES, 2008 apud CASTELO BRANCO, 2015).

Seguindo esta trilha de raciocínio, ainda é de bom tom acrescentar as palavras de Castelo Branco (2015):

\begin{abstract}
O estereótipo dos etiquetados como criminosos no Brasil engloba (de forma geral) as características observadas por Nina Rodrigues e, posteriormente, foi sendo complementado por outras categorias: criminoso/homem $=$ doente $=$ degenerado $=$ violento $=$ negro $/$ mestiço $=$ pobre/excluído. Nessa lógica matemática, o código hegemônico da violência não casualmente coincide com a descrição de alguns crimes no Código Penal, com as lições manualescas da criminologia tradicional e com a seletiva clientela do sistema penal.
\end{abstract}

A periculosidade passou a ser entendida, desde então, como o grau de probabilidade do impulso criminal do indivíduo. A fim de se garantir a manutenção de uma ordem social, utilizam-se estratégias de criminalização de classes consideradas potencialmente perigosas, práticas estas institucionalizadas. Assim, o "louco infrator", torna-se categoria duplamente estigmatizada "ao ser entendido não apenas como portador de um transtorno mental, já regido por seus próprios estigmas, mas também como indivíduo criminoso que possui na periculosidade de suas ações a instabilidade que fere diretamente as expectativas sociais pré-determinadas" (CAIXETA, 2012). É neste momento que medida de segurança se configura como um instituto que pune a loucura.

Nesse sentido, Castel (1987) atém-se, basicamente, em analisar as condições concretas da produção da loucura como objeto de saber (na linha de Foucault) legitimado por instituições socialmente reconhecidas que terminam por formar um campo específico. O autor descreve as contradições da Psicanálise e da Psiquiatria. A partir do pós-guerra, questiona-se o isolamento - como também os "maus tratos" - no hospício e procura-se dissolver esse monopólio médico, favorecendo a permanência do então "portador de transtorno mental" em sua casa, vizinhança através da partilha dos cuidados com familiares e vizinhos, principalmente, formulando outro saber para tanto a "atenção psicossocial"”.

Para Szasz (1977), com o surgimento da ideologia americana da saúde mental que consiste na ideologia psiquiátrica tradicional, envernizada com algumas palavras novas, simplificada para o consumo geral, e endossada pelas profissões terapêuticas, pelos legisladores, cortes, igrejas e assim por diante, estabeleceu-se um tipo de consumo geral que emerge como senso comum evidente. Como Deus e diabo eram símbolos-chave 
da ideologia teológica medieval, assim também a sanidade e insanidade mental são símbolos-chave da ideologia psiquiátrica americana. A dicotomia do bem e do mal é agora substituída pela dicotomia da saúde e da doença mental. É nesse momento que a noção do mal é agregada à doente mental.

Assim, surgem antinomias típicas como:

O movimento da saúde mental contra o movimento anti saúde mental, psicoterapeutas que desejam curar contra pacientes que se recusam a serem tratados; criminosos que assim são por serem doentes contra aqueles que são delinqüentes por escolherem ser maus; e assim por diante. (SZASZ, 1977).

Mais especificadamente, a ideologia da saúde e doença mental não somente serve para explicar toda espécie de enigmas, mas também aponta o caminho para sua solução. A ideologia de saúde serve para classificar e para fornecer um caminho satisfatório de controle. Se pudesse haver uma definição precisa de doença mental, é possível que nenhum psiquiatra ou psicólogo fosse chamado a diagnosticá-la, talvez, qualquer pessoa inteligente poderia fazê-lo. Contudo, devido a que doença mental é indefinida, a pessoa que tem responsabilidade social de determiná-la é chamada não a constatar fatos, mas para criar uma definição e exercer o controle social.

O diálogo social corrente entre os juízes (e legisladores), por um lado, e psiquiatras(e psicólogos) por outro, pode ser parafraseado como segue:

Os juristas declaram: há dois tipos de criminosos: um, os mentalmente insanos, o outro os mentalmente sãos. Cabe os psiquiatras (e psicólogos), determinar quem pertence a qual dos grupos. Eles devem ajudar a nós e a sociedade, livrando-nos dessa importante obrigação profissional (SZASZ, 1977).

Cabia ao jurista codificar e dar uma forma unificada ao país, sendo o médico apenas um técnico que auxiliaria no desempenho daquele profissional. Confortar-se com a crença de que, em nome progressista, o confinamento numa instituição psiquiátrica é, na realidade, o mesmo que em qualquer outro tipo de hospitalização. Porque, apesar de demonstrarmos maior compaixão e compreensão com relação aos insanos do que alguns de nossos antepassados, o fato é que a pessoa diagnosticada como mentalmente insana é estigmatizada particularmente se for confinada num hospital psiquiátrico público. "Esses estigmas não podem ser removidos pela "educação" da saúde mental, porque a raiz do problema é a nossa intolerância para com certos tipos de comportamento" (SZASZ, 1977).

Percebe-se que há uma dupla punição quando a maioria das pessoas consideradas insanas mentalmente (especialmente aquelas confinadas involuntariamente) 
são assim definidas por seus parentes, amigos, ou talvez pela polícia, e não por si próprias. Perturbaram a ordem social, desconsiderando as convenções da sociedade educada ou vedando leis, assim nós rotulamos como “doentes mentais" e punimo-las pela internação numa instituição psiquiátrica. O paciente sabe que está privado de liberdade porque tem incomodado os outros, não porque esteja doente. E, no hospital psiquiátrico, aprende que, enquanto não modificar seu comportamento, será segregado da sociedade. Mas, mesmo que se modifique e seja autorizado a partir, o registro de seu confinamento vai consigo e as consequências práticas são mais as de uma estada na prisão do que num hospital.

O prejuízo psicológico e social, assim acarretado frequentemente, ultrapassa de longe os benefícios de qualquer terapia psiquiátrica. A função dos hospitais é bem fácil de identificar: ajuda nas dificuldades pessoais; ajuda às famílias e à sociedade a se tratarem daqueles que a aborrecem e protege a sociedade e o "paciente jurídico" dele mesmo. Essa função, como percebido, é favorável a todos, menos a quem ela é destinada: ao "doente mental".

Quando se fala de doença, frequentemente se pensa em duas coisas bastante distintas: primeiro, que o paciente apresente uma condição biológica ("anormal"); segundo; que ocupe certo papel social (“desviado"). O paciente hipotético acima mencionado apresenta sinais e sintomas de sua condição biológica. Segundo Foucault ( 1991), hoje não se julga mais sozinho o fenômeno da loucura, recaindo não apenas nos juízes o poder de classificação e deliberação, ou mesmo nas famílias dos loucos criminosos. Fraciona-se o poder legal de punir; a Psicologia e Psiquiatria ganham também espaço de normatização das práticas interventivas. "É de interesse tanto da Psiquiatria como do Direito definir quais papéis são socialmente legítimos e quais não os são, e de impor conformidade aos papéis prescritos" (SZASZ, 1977). A Psiquiatria institucional impõe conformidade de papel, definindo o desvio deste como doença mental punível pelo confinamento.

\section{CONSIDERAÇÕES FINAIS}

O propósito principal deste artigo foi apresentar e analisar o instituto das medidas de segurança, embasado não no texto penal codificado ao qual ela pertence, mas 
em uma análise histórica desde o surgimento da periculosidade (um dos pressupostos que a sustenta) até a criminalização da loucura como meio de defesa social. Percebeu-se que foi através do discurso da chamada doença mental que se justificou e autorizou a exclusão social. Prisões, manicômios, hospitais psiquiátricos e de custódia foram os espaços eleitos de segregação daqueles infratores da ordem e segurança social, os quais se configuram (ainda hoje) como um verdadeiro "palácio de guardar doidos".

Notou-se que as normas as quais são submetidos os chamados "loucos infratores" não possuem somente uma (in)eficácia instrumental, mas também simbólica, ao reduzir a voz das pessoas submetidas à medida de segurança a uma voz administrada pela psiquiatria e pelo direito. Percebe-se, assim, que ela serve como forma de fixar e congelar a identidade do paciente jurídico, sendo que a administração de sua fala se dá pela Psiquiatria.

Ao longo deste artigo buscou-se discutir as possibilidades de classificação social quanto à sua forma de entendimento da relação entre o crime e a loucura, através da medida de segurança. Foi no campo histórico, bibliográfico e científico que se buscou entendimentos para que se chegasse a uma conclusão sobre tal instituto, mas o que se encontrou foram mais indagações que serão tratadas em oportunidade futura. À luz da medicina social e da criminologia crítica, foram discutidos diversos pontos da institucionalização das medidas de segurança efetivadas na ideia de punir a loucura e como matriz de defesa social. Ainda que a atual legislação brasileira já aponte para um deslocamento da matriz de defesa social para uma matriz dos direitos humanos, no que tange às práticas de assistência à pessoa com transtorno mental, não é o que acontece ainda no trato penal ao "louco infrator". As novas resoluções quanto à sociabilidade dos sujeitos e à reintegração social residem nos discursos; na prática, nota-se que o percurso histórico da constituição do chamado "louco criminoso" ainda se pauta em aspectos de asilamento ao tratamento, tutelados tanto pelos âmbitos normativos do direito penal, quanto da ciência médica psiquiátrica.

Diante do apresentado, notou-se, por fim, que a medida de segurança está para o "louco infrator" como um pêndulo para um relógio antigo: oscila sempre entre dois polos por onde ela circula e não sabe qual polo seguir.

Ela está entre a pena e o tratamento; é cumprida entre um presídio e um hospital; a pessoa que se submete a ela é um preso, mas também um doente - é uma pessoa sã, mas também uma pessoa insana. Estar submetido a ela é uma proteção, mas 
também um perigo; é medir um tempo que está entre o determinado e o indeterminado; faz falar de essência e aparência, de verdade e mentira. Do mesmo modo, a medida de segurança fala também de perigo e de necessidade, necessidade de contenção de entes perigosos que vai sempre além dos limites legais.

Um campo de batalha: a criminalização da loucura se configura, assim, como um sombrio campo de batalha. No campo de batalha, independente do motivo de uma, os convocados, a maioria a contragosto, nunca podem estar felizes e, neste momento, os combatentes demonstram eterna tensão e dificuldades de combater em ambiente inóspito. Os senhores de guerra rivais reúnem os seus guerreiros mais poderosos. O campo de batalha cheira a morte, sofrimento e dor.

Não diferente é a criminalização da loucura (medidas de segurança). Fundamentada em uma periculosidade (indefinida e ambígua), a maioria dos pacientes são internados a contragosto, a fim de proteger quem mais o exclui: a família, sociedade; o próprio sistema. Tais pacientes nunca podem estar felizes. Trancafiados em verdadeiros abatedouros humanos, demonstram eterna tensão e dificuldade em sobreviver num ambiente inóspito. Os senhores da guerra (psiquiatras/legisladores: o Estado) reúnem seus guerreiros mais poderosos (laudo pericial e o texto penal brasileiro). Está traçado o campo de batalha, só que, aqui, há uma paradoxal batalha de defesa social da pessoa portadora de doença mental contra a sua própria loucura. Como nos campos de batalha, alguém vencerá; nesse caso, a cultura do medo.

\section{REFERÊNCIAS}

ALENCAR, José de. Senhora. _Rio de Janeiro: L\&PM Pocket, 1875.

ANDRADE, Vera Regina Pereira de. Sistema penal máximo x cidadania mínima: códigos da violência na era da globalização. Porto Alegre: Livraria do Advogado, Editora, 2003.

ANITUA, Gabriel Ignacio. Histórias dos pensamentos criminológicos/Gabriel Ignácio Anitua; tradução Sérgio Lamarão. Rio de Janeiro: Instituto Carioca de Criminologia, 2008.

BARATTA, Alessandro. Criminologia crítica e crítica do direito penal: introdução à sociologia do direito penal. Tradução Juarez Cirino dos Santos. Rio de Janeiro: Revan, 2002 . 
BECCARIA, Cesare. Dos delitos e das penas. São Paulo: EDIJUR, 2003.

BECKER, Howard S. Outsiders "Estudos de Sociologia do Desvio". Zahar, Rio de Janeiro, 2008.

CASTELO BRANCO, Thayara Castelo. A (Des)legitimação das medidas de segurança no Brasil -Belo Horizonte: D'Plácido, 2016.

O exame de periculosidade do agente e a criminalização da doença mental no direito brasileiro: apontamentos críticos. XIX CONPEDI, Fortaleza-CE, junho 2010. Disponível em:

http://www.observasmjc.uff.br/psm/uploads/O_exame_de_periculosidade_do_agente_e acriminaliza\%C3\%A7\%C3\%A3o_da_doen\%C3\%A7a_mental_no_direito_brasileiro_a pontamentoscr\%C3\%ADticos.pdf. Acesso em: 20/10/2016.

\section{. A Herança de Nina Rodrigues no Tratamento dos Portadores De}

Sofrimento Psíquico Submetidos ao Sistema de Justiça Criminal Brasileiro. in.: Constituição e Direitos Fundamentais em Perspectiva. Appodi, 2015. Disponível em: http://www.unicap.br/biblioteca/pages/wpcontent/uploads/2015/09/Constitui\%C3\%A7 \%C3\%A3o-de-direitos-fundamentais.pdf. Acesso: 20/10/2016.

CAIXETA, Izabela Amaral. Entre a criminalização da loucura e a psiquiatrização do crime: as trajetórias da medida de segurança no Distrito Federal. 2012. 109 f.

Monografia (Bacharelado em Sociologia) —Universidade de Brasília, Brasília, 2012.

CASTEL, Robert. A gestão dos riscos - da antipsiquiatria à pós-psicanálise. Rio de Janeiro, Francisco Alves, 1987.

CORREA, Mariza. Raimundo Nina Rodrigues e a "Garantia da Ordem Social”. REVISTA USP, São Paulo, n.68, p. 130-139, Dezembro/Fevereiro 2005-2006.

DOTTI, René Ariel. Penas e medidas de segurança no anteprojeto de código penal. In:_. Revista de Direito Penal. Rio de Janeiro: Forense, 1982.

FOUCAULT, Michel. Microfísica do Poder/Michel Foucault; org. e trad. de Roberto Machado- Rio de Janeiro: Edições Graal, 1979. ISBN 85-7038019-4

“Verdade e as Formas Jurídicas”. Rio de Janeiro: Nau Editora, 2003.

“Vigiar e punir: história da violência nas prisões"/Michel Foucault; trad. de Raquel Ramalhete. Petrópolis, Vozes, 1987.

"Doença Mental e Psicologia"; trad. de Lilian Rose Shalders Rio de Janeiro, Tempo Brasiliero,1975.

GONÇALVES, Renata Weber. A medida de segurança: elementos para interpretação da contenção por tempo indeterminado dos loucos infratores no Brasil. 2008. $111 \mathrm{f}$. Dissertação (Mestrado em Antropologia)-Universidade de Brasília, Brasília, 2008. 
JACOBINA, Paulo Vasconcelos, Direito Penal Da Loucura: Medida De Segurança e Reforma Psiquiátrica; Revista de Direito Sanitário, vol.5, n.1, Mar/2004.

LOMBROSO, Cesare. O homem delinquente/Cesare Lombroso; trad. Sebastião José Roque. São Paulo: Ícone, 2013. (Coleção fundamentos de direito).

MACHADO, Roberto. Danação da Norma: Medicina social e constituição da psiquiatria no Brasil, Rio de Janeiro, Graal,1978.

MARCÃO, Renato. Curso de execução penal. 6. Ed. Saraiva, 2008.

MARCHEWKA, Tânia Maria Nava. As contradições das medidas de segurança no contexto do direito penal e da reforma psiquiátrica no Brasil. In:_. Revista da Associação Brasileira de Professores de Ciências Penais. São Paulo: Editora Revista dos Tribunais, 2004.

MARQUES, José Frederico. Tratado de Direito Penal. Campinas: Millennium, 1999.

RIBEIRO, Bruno de Morais. Defesa Social, Ideologia do Tratamento e o "Direito Penal do Inimigo”. In.:Revista de Ciências Jurídicas. v. 6. n.1 jan./jun, 2008.

Disponível em:

http://eduem.uem.br/ojs/index.php/RevCiencJurid/article/view/9027/5022. Acesso em: 25/11/2016.

RODRIGUES, Raimundo Nina. Mestiçagem, degenerescência e crime. In:_. História, Ciências e saúde - Manguinhos, vol. 15, n² . Rio de Janeiro, 2008. Disponível em: http://www.scielo. br/scielo.php?pid=S0104-59702008000400014\&script=sci_arttext . Acesso em: 20/01/2017.

SANTOS, Juarez Cirino dos. Direito penal: parte geral. Curitiba: Lumen Juris, 2006.

SZASZ, Thomas S.. Ideologia e Doença Mental: Ensaios sobre a desumanização psiquiátrica do homem. Rio de Janeiro, Zahar, 1977.

ZAFFARONI, Eugenio Raúl. Em busca das penas perdidas: a perda da legitimidade do sistema penal, Rio de Janeiro, Revan, 1991. 